\title{
Einstein's revisions and new dimension caused big bang and soul
}

\author{
Yahachiro Matsushita \\ 2-37 Ikeda 5 Chome Niiza-Shi, Saitama-Ken, Japan
}

\section{Email address:}

yahatiro-m@mx4.ttcn.ne.jp

\section{To cite this article:}

Yahachiro Matsushita. Einstein's Revisions and New Dimension Caused Big Bang and Soul. Advances in Biochemistry. Vol. 1, No. 4, 2013, pp. 57-63. doi: 10.11648/j.ab.20130104.11

\begin{abstract}
The cosmos was created to expand extraordinarily high heat by the big bang. Elementary particles of those essence cause space and temperature as an acceptor of heat. Forming and demolition of molecules by them show life and death, giving the essence of life called soul too. Molar heat $(\mathrm{Cp}$ )and temperature $(\mathrm{K})$ connect with $1 \%$, which means a concrete entropy .Existence of elementary particles gives $-653 \mathrm{~K} . \alpha$ of thermal expansion has the best factor for new dimension , giving entropy ,time, temperature, space and additional properties .Einstein's equation on Brownian movement shows a movement of water molecule. New viewpoint changes that cause those thermal expansion or shrinkage. A little different temperature at local places of water happen Brownian movement .New dimension by $\alpha$ targets to change size of three axis in 3D. Molecule groups above $0 \mathrm{~K}$ are formed 3D, which separate 8 groups in one level, giving unit temperature $39 \mathrm{~K}$. Up to $-653 \mathrm{~K}$. from $0 \mathrm{~K}$, modified value consists of 17 levels obtained from $39 \mathrm{~K}$. This is correspondent to numbers of elementary particles 17 . This would be to make a confirmation of the theory. $1 \mathrm{~L}$ of molecules is this world and over $2 \mathrm{~L}$ is separated soul world. Soul could take any time and size of space an instant and travel in the past and future .Soul of higher level is able to have more long time than lower one. Although from lower level can't move up the upper rank, the opposite is possible because high level has all $\alpha$ of lower level. Final level of 18L, the highest spirit, can transfer to all level, all souls encounter with $1 \mathrm{~L}$.Elementary particles in everywhere prove dark matter. A circular movement of gas molecule gives the reason of the dark without flowing away as light. The flow of elementary particles which circulates through the surface of earth generates the gravitation. A material falls to flow down riding on them. A light of composite rays, with each different velocity, cause to make the order in a close time by a circular course .This understanding gives a possibility a existence of over the velocity of light in the light. Relation the starting point and time is uncertainly by new understanding of Heisenberg's principle. Over the velocity of light belongs a theoretical field.
\end{abstract}

Keywords: Temperature, Brownian Movement, Entropy, Thermal Expansion Rate, Dimension, Big Bang, Gravitation, Elementary Particles, Heisenberg's Principle, Dark Matter

\section{Introduction}

Einstein is the one who was in the past. Today, lot of important physical fact has been found out, which are confirmation of the big bang and elementary particles .It gives the revisions and new theory for Einstein's theory. The cosmos was created to expand extraordinarily high heat by the big bang. There is a different meaning for heat and temperature .The traditional thermo-dynamic have been done in heat, which gives a abstract and difficult content without practical use .Here is shown, temperature is the key part as acceptor of heat, which gives a concrete content .Because a acceptor of spreading heat existed, space and temperature .happened . If it were nothing, heat would pass without dropping in there To be precise, elementary particles having extraordinarily high heat mean to spread. In case of above $0 \mathrm{~K}$, molar heat $\left(\mathrm{C}_{\mathrm{p}}\right)$ are made by elementary particles having heat quantity. Heat of $\mathrm{C}_{\mathrm{p}}$ and temperature of $\mathrm{K}$ and ${ }^{\circ} \mathrm{C}$ connect with $1 \%$, which means a concrete entropy .That shows large size has higher $C_{p}$ than small .Existence of elementary particles, exceptional small, needs under current absolute zero .Living thing is composed of macro-molecule of amino compound mainly, which their-self is made by elementary particles. Although death of living thing bring to distinguish macro-molecule, elementary particles don't disappear to stay. Coming and going of them show life and death .Elementary particles mean the essence of life, called as soul Thinking new 
dimension, it needs to introduce this important fact. Up and down of temperature originate from elongation, including shrinkage, between atoms of molecule, which heat quantity come and go. First elongation starts by thermal movement, but the movement stops when it reaches $1 \%$ elongation. New heat quantity adds furthermore, it happens mechanical movement so that it changes from vertical direction to horizontal .A similar occurrence seems to develop in the early the big bang. When heating exceeded $1 \%$ in elementary particles group, the big bang start suddenly in violent mechanical movement. The flow of heat from the big bang stays $\alpha$ in the final elongation of atom, making the heat balance to cause functional phenomena. Where $\alpha$ is linear coefficient of thermal expansion. $\alpha$ is a almighty factor ,which is related to both movement and temperature ,connecting to the mechanism and functions of materials and the time of process .To understand easily ,a concrete example is shown as follows. At a fixed temperature , $\alpha$ is given as $. \alpha=\Delta \mathrm{L} / \mathrm{L}$ Where $\Delta \mathrm{L}$ is expanded length, $\mathrm{L}$ is length of element. Even if $\Delta \mathrm{L}$ of both are different such as $1 \mathrm{~km}$ and $1 \mathrm{~cm}, \alpha$ can take the same value of $1 \%$, through $\mathrm{L}$ is $100 \mathrm{~km}$ and $100 \mathrm{~cm}$. Therefore, $\alpha$ can deal with as a common function in phenomena which

a

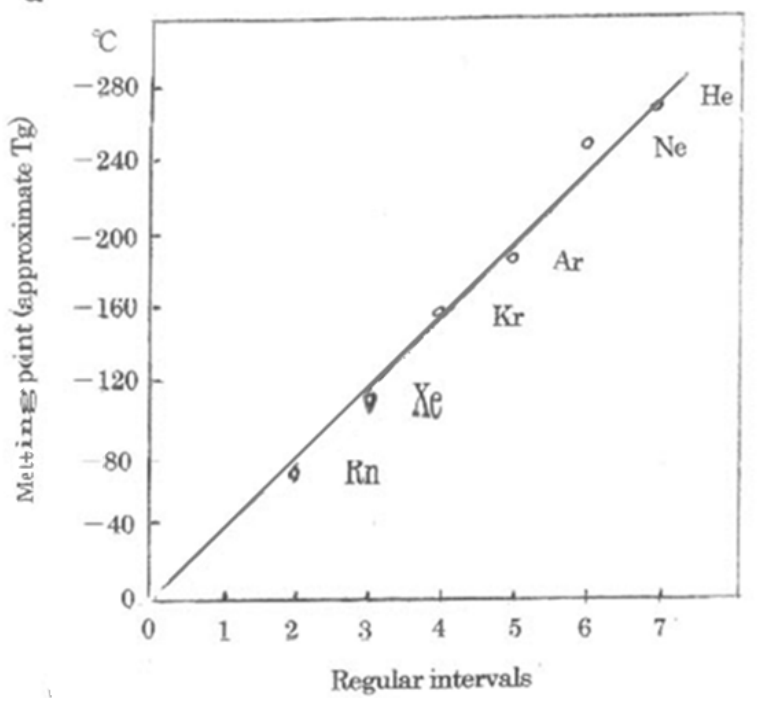

exist from macro-field of cosmos to micro-one of atoms and elementary particles by changing L. Moreover, $\alpha$ has the adding property, $\alpha$ is component element can add. $\alpha$ of molecules are formed to add up $\alpha$ of component atoms, which is connected to $\alpha$ of elementary particles as well. The comparison of $\alpha$ among materials in each state have utility value.$\alpha$ is only factor giving a accurate answer for the nature of the cosmos. Here is shown that $\alpha$ has the key part in discussion of dimension and the mechanism of elementary particles through gas molecule. The elongation of molecule is reported as follow. The happening elongation in $\mathrm{C}-\mathrm{C}$ bond has been clarified through thermal behavior of polymer [1][2].They are classified in two sorts. One is given by thermal movement between atoms and the other is mechanical one. Gases and liquids appear from the stop of thermal movement, which temperature of turning point is called as $\mathrm{Tg}$ (the glass-transition temperature).. In case of below $0{ }^{\circ} \mathrm{C}, \mathrm{Tm}$ (approximate $\mathrm{Tg}$ ) among gases at 18 family element in the periodic table is dotted on a line from ${ }^{\circ} \mathrm{C}$ to $0 \mathrm{~K}$,which consists of 7 block having a regular intervals $39^{\circ} \mathrm{C}$ shown as Fig. 1a .Equation of below $0^{\circ} \mathrm{C}$ is given as

$$
\alpha=1 \% \cdot \operatorname{Tg}\left({ }^{\circ} \mathrm{C}\right)
$$

b

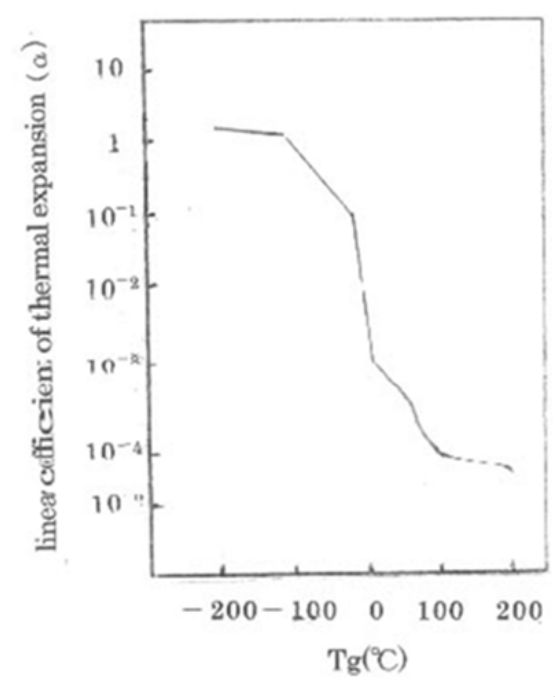

Fig 1. The relation between $\alpha$ and $T g$.

(a)The orderly melting point among gases at 18 family element in the periodic table. Figure shows that Tm (approximate Tg) among gases is dotted on a line from $0{ }^{\circ} \mathrm{C}$ to $0 \mathrm{~K}$ and near each block divided into 7 . Each element belongs to a different electric shell. Because there is only a little difference between Tm and boiling point on the whole that is a characteristic in 18 family element, Tg seems jumping to Tm immediately.. (b) A diagram of $\alpha$ vs $\mathrm{Tg}\left({ }^{\circ} \mathrm{C}\right)$ connecting up and down $0{ }^{\circ} \mathrm{C}$. A diagram shows a transformation compressing the upper value due to a wide extent. The equation over $0{ }^{\circ} \mathrm{C}$ provides $\alpha \cdot$ Tg $\left({ }^{\circ} \mathrm{C}\right)=1 \%$ Because in less than $1^{\circ} \mathrm{C}$ is an inflection point, it cannot use from $1^{\circ} \mathrm{C}$ to $0^{\circ} \mathrm{C}$ with indefiniteness.

$\operatorname{Tg}\left({ }^{\circ} \mathrm{C}\right)$ is an absolute value. $\mathrm{Tg}$ below $0{ }^{\circ} \mathrm{C}$ can handle as normal temperature. Therefore, (1) changes to general equation as

$$
\alpha=1 \% \cdot \mathrm{t}\left({ }^{\circ} \mathrm{C}\right)
$$

Although (2) starts from $0^{\circ} \mathrm{C}$, absolute zero can take it. In that case, $\mathrm{t}\left({ }^{\circ} \mathrm{C}\right)$ is $\mathrm{t}(\mathrm{K})$.In case of starting from $0 \mathrm{~K}$, elongation between atoms becomes $\alpha$. Because length of element, which is a denominator in ratio, is value of atom itself at $0 \mathrm{~K}$, which seems to be constant value common among atoms .Fig. $1 \mathrm{~b}$ shows a diagram of $\alpha$ vs. $\operatorname{Tg}\left({ }^{\circ} \mathrm{C}\right)$ connecting up and down $0{ }^{\circ} \mathrm{C}$. Tg vs. $\mathrm{C}_{\mathrm{p}}$ among gas molecules was found to have a $-1 \%$ gradient shown as Fig. 2a. The value of $\mathrm{C}_{\mathrm{p}}$ exists in $273 \times 10^{-1} \mathrm{~J}(6.53 \mathrm{cal})$ at $0 \mathrm{~K}$. Elementary particles formation starts at $-926^{\circ} \mathrm{Cobtained}$ by $\left(653^{\circ} \mathrm{C}+273^{\circ} \mathrm{C}\right)$. Where $653^{\circ} \mathrm{C}$ converts from 6.53 cal at 
$0 \mathrm{~K}$. The origin of temperature is $-926{ }^{\circ} \mathrm{C}$.Equation

$\mathrm{C}_{\mathrm{p}}(\mathrm{cal})=6.53+1 \% \operatorname{Tg}(\mathrm{K})$ between $\mathrm{C}_{\mathrm{p}}$ and $\operatorname{Tg}(\mathrm{K})$ is given as

a

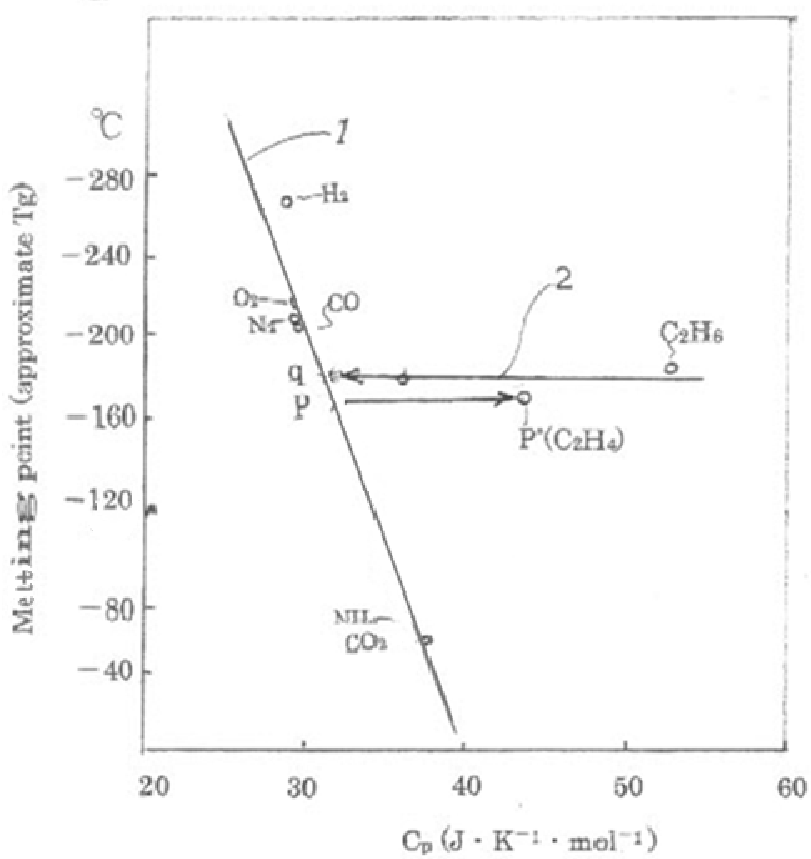

b

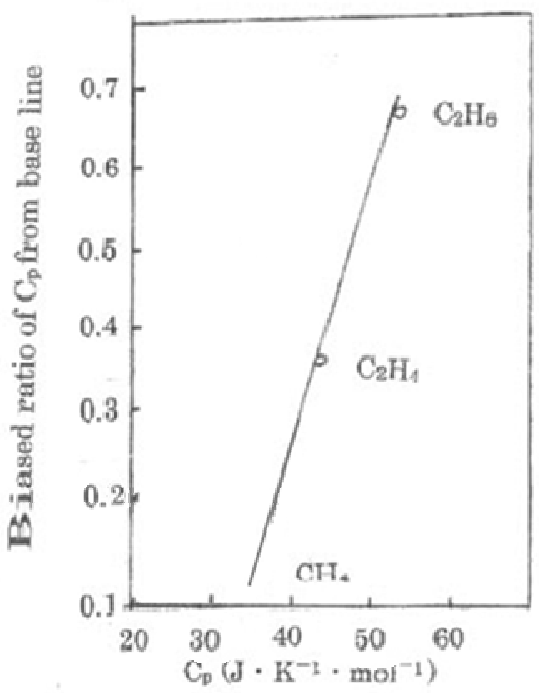

Fig. 2. Relation between $C_{p}$ and $T g$

(a)Figure shows Tm (approximate Tg) vs. $C_{p}$ among gas molecules, which gives a base line 1. The gradient of a straight line is obtained from any value on the line. \{upper $C_{p}(28.0)-$ lower $\left.C_{p}(38.0)\right\} /\left\{\mathrm{Tg} /-280^{\circ} \mathrm{C} /-\mathrm{Tg} /-40^{\circ} \mathrm{C} /\right\}=-4.16 \% \mathrm{~J}$, or $-1 \%$ cal.. (b) Figure shows biased ratio to line 1 . The line 2 shows gas molecules diverged from the base line 1. An example of calculation is given from $\mathrm{C}_{2} \mathrm{H}_{4}$ as follows . Divide the difference of $\mathrm{C}_{p}$ between $p$ 'and pon line 1 by $C_{p}$ of p', that is $(43.63-32.0) / 32.0=0.363$. The line of biased ratio indicates to start from $q$. Where $q$ is a fictitious starting point of line 2

This proves the existence of $1 \%$ elongation limit in below $0 \quad{ }^{\circ} \mathrm{C}$. This theory is reasonable because elongation $(\alpha)$ connects temperature $(t)$ and heat $\left(\mathrm{C}_{\mathrm{p}}\right)$ with $1 \%$ elongation limit common among atoms . $\{3\}$

\section{Thermal Expansion of Molecule Cause Brownian Movement}

Brownian movement of water have been thought to be a peculiarity of active movement in molecule by Einstein, who gave the equation, (6). But, it is not clear how to get molecules of water a movement .It's unthinkable that they can move like a living thing. Moving a particle with zigzag needs a group force with a specific structure by a chain of molecules called as cluster. To understand easily, a moving of cluster causes by heat .Even if a measurement is done at a fixed temperature, the perfect temperature control is impossible. A slight difference of temperature generating in everywhere happen a movement of them. From Einstein's equation is given the gas equation caused by heat ,shown as thermal expansion, as follows .If a average displacement of particles by Brownian movement is given as $\mathrm{x}, \mathrm{y}$, which is considered to be a displacement of cluster of water molecules, a existence of $x^{2}=y^{2}$ given as (4) is known . Fig. 3 shows a observation looking down from Y-axis. If the base of a right triangle $(\mathrm{OP})$ is $\mathrm{x}$, hypotenuse $(\mathrm{OQ})$ is $\mathrm{R}$ and altitude ( $\mathrm{PQ}$, it is equal to $\mathrm{OO}^{\prime}$ on $\mathrm{Y}$-axis)is $\mathrm{y}$, it is shown as $\mathrm{R}^{2}=\mathrm{y}^{2}+\mathrm{x}^{2} \quad$.R becomes $\mathrm{x}$ because of projection looking down from $Y$-axis. If $y$ changes, $x$ gives different though $R$ doesn't change. Even if $x, y$ differ, their square is equal because of.(4) .The volume expansion rate of water molecule causes equal movement in all direction. Therefore, $\mathrm{R}$ means the radius of a sphere and is given by ;

$$
\mathrm{R}^{2}=2 \mathrm{x}^{2}=2 \mathrm{y}^{2}
$$

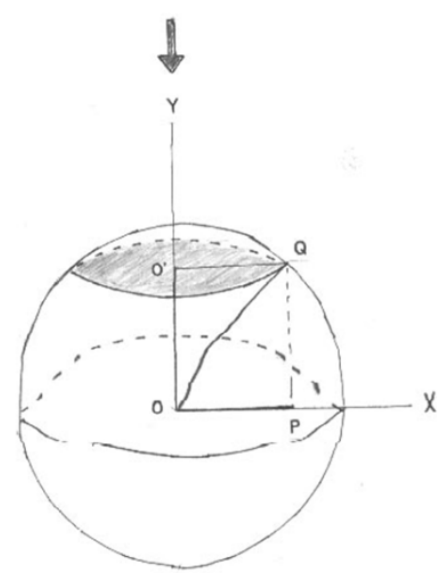

Fig. 3. Brownian movement 
Figure shows a observation looking down from Y-axis. A average displacement of particles by Brownian movement shows $x, y$. The base of a right triangle(OP) is $\mathrm{x}$,hypotenuse $(\mathrm{OQ})$ is $\mathrm{R}$ of a radius and altitude $(\mathrm{PQ}$, it is equal to OO'on Y-axis) is $y$.Because $x^{2}=y^{2}$ is the condition, the movement of particles is observed the radius of a circle $\mathrm{O}^{\prime}$ though the fact is the one of a circle $\mathrm{O}$.

A displacement of water cluster by expansion of sphere gives the same movement as air molecules. [3] The new viewpoint also makes Einstein's (6) change to the gas equation (7) .[4]

$$
(\Delta \mathrm{x})^{2} / 2 \tau=\mathrm{RT} / \mathrm{Nf}
$$

Where $\tau$ is time, $\mathrm{N}$ is Avogadro's number and $\mathrm{f}$ is coefficient of friction which give a necessary velocity of 1 $\mathrm{cm} \mathrm{sec}{ }^{-1}$ to particle. Theoretical $(\Delta \mathrm{x})^{2}$ can separate into dynamic and thermal factors. The former is $\Delta \mathrm{x}$ of displacement and the latter is $\Delta \mathrm{x}=\alpha \Delta \mathrm{t}$. Where $\mathrm{t}$ is temperature $\left({ }^{\circ} \mathrm{C}\right)$ from $0^{\circ} \mathrm{C}$.From $\Delta \mathrm{x}$ of displacement gives velocity of $\Delta \mathrm{x} / \tau$ in (5) and brings stress $\mathrm{P}$ of (f $\cdot \Delta \mathrm{x} /$ $\tau)$.From thermal $\Delta \mathrm{x}$ gives volume $(\Delta \mathrm{V})$ through $\Delta \mathrm{V} \propto$ $\alpha \Delta \mathrm{t}$.That brings next equation per $1 \mathrm{~mol}$, which is similar to gas equation,

$$
\mathrm{PV}=\mathrm{kRT}
$$

Where $\mathrm{k}$ is constant .Even if water is given as a constant temperature, which is the mean actually, the local places happen a little up and down temperature $(\Delta \mathrm{t})$. Therefore, Brownian movement originates in rather thermal expansion or shrinkage of water cluster by $\Delta t$ than the movement itself. Liquids and gases have the same mechanism and the difference of $\alpha$ separates the two.

\section{Dimension}

It has been attempted to clarify the structure of the cosmos by dimension. A fourth dimension(4D) has been interpreted as continuous thing of time and space, adding time to 3D by Einstein. This idea is distinguished because traditional high dimension deals with space only .But there are two problems. Time given as distance / velocity, is not a element of dimension because of attendant of the both, distance and velocity. The other means that deny all spaces by non-Euclidean geometry in high dimension.

\subsection{Dimension Including the Big Bang and Soul}

The cosmos was created to expand extraordinarily high heat of the big bang. Theoretical bases of everything need to take the fact, implying a answer of dimension too. Elementary particles of heat acceptor make molecules, which give $3 \mathrm{D}$ space and molar heat $(\mathrm{Cp})$, forming a temperature from the thermal elongation of them, including shrinkage. A temperature connect heat quantity through $1 \%$ elongation limit of $\alpha$. $\alpha$ gives a common factor for the distance of space and temperature . $\alpha$ is the most suitable for a study of dimension. Elementary particles also mean the essence of life, called soul Thinking new dimension, it needs to introduce this important fact ..

\subsubsection{Elementary Particles and the Total Numbers 17}

The existence of elementary particles are indispensable for the thought of dimension. If the total numbers of new dimension is the same value, it would be to make a confirmation of the theory. Elementary particles consist of 17 elements, which are 6 quarks, proton, neutron, and 6 leptons ,electron ,neutrino, and 5 others , including Higgs's particle.

\subsubsection{Thermal Expansion ( $\alpha$ ) meet Space and Time $\alpha$ is given by (8) .}

$$
\alpha=(\Delta \mathrm{L} / \mathrm{L}) / \mathrm{t}
$$

Where $\Delta \mathrm{L}$ is expanded length, $\mathrm{L}$ is length of element and $\mathrm{t}$ is temperature .Equation (8) brings (9) as $\mathrm{L}$ is constant.

$$
\alpha=\Delta \mathrm{l} / \mathrm{t}
$$

Where $\Delta \mathrm{l}=\Delta \mathrm{L} / \mathrm{L} . \Delta \mathrm{l}$ shows the target length and element of space. Equation(10)shows velocity (V) .

$$
\mathrm{V}=\Delta \mathrm{l} / \mathrm{T}
$$

Where $\mathrm{T}$ is time In case of fixed temperature, from (9),(10) brings (11) .

$$
. \alpha=\mathrm{VT}=\Delta \mathrm{l}
$$

Equation (11) shows an impotent content to connect with the factor of time. Increasing $\alpha$ means to increase velocity (V) or time length(T).$\alpha$ also has the adding property as follows.$\alpha$ of molecule is given as,$\alpha=\Sigma \alpha$ ifi Where $\alpha i$ is $\alpha$ of component $\mathrm{i}$ atom and $\mathrm{fi}$ is the volume ratio. Big bang gives a temperature $(\mathrm{t})$ and space $(\Delta \mathrm{l})$ based on elementary particles, forming dimension and $\alpha$ appears that through.(9),(11) .

\subsection{New Thought of Dimension and Borderline of $0 K$}

Although the space is given as $3 \mathrm{D}$, traditional high dimension used to handle its deformation New thought takes expansion, including shrinkage, of 3D. The existence of elementary particles shows $-653 \mathrm{~K}$. Above $0 \mathrm{~K}$ which molecules form and under $0 \mathrm{~K}$ can be separated by $\alpha$, making a borderline.

\subsubsection{Temperature Limit of One Group in Above $0 \mathrm{~K}$}

The periodic law shows 7 period between elemental 8 groups, see Fig.1a. Each element of group belongs to a different electric shell. So a temperature range of group provides $273^{\circ} \mathrm{C} / 7=39^{\circ} \mathrm{C}(39 \mathrm{~K})$

\subsubsection{Temperature Under $0 \mathrm{~K}$}

Relation between temperature $(\mathrm{Tg})$ and molar heat $\left(\mathrm{C}_{\mathrm{p}}\right)$ among gas molecules was found to have a $-1 \%$ gradient shown as Fig. $2 \mathrm{a}$. These give next two facts. The value of $\mathrm{C}_{\mathrm{p}}$ exists in $273 \times 10^{-1} \mathrm{~J}(6.53 \mathrm{cal})$ at $0 \mathrm{~K}$. It suggests that there is 
latent temperature under $0 \mathrm{~K}$ and means energy which atom itself have. Atom formation starts at $-926^{\circ} \mathrm{C}$ obtained by $\left(653^{\circ} \mathrm{C}+273^{\circ} \mathrm{C}\right)$. Where $653{ }^{\circ} \mathrm{C}$ converts from 6.53 cal at $0 \mathrm{~K}$. The origin of temperature is $-926^{\circ} \mathrm{C}$ theoretical ,though temperature under $0 \mathrm{~K}$ cannot take out . Equation between $\mathrm{C}_{\mathrm{p}}$ and $\operatorname{Tg}(\mathrm{K})$ is given as $\mathrm{C}_{\mathrm{p}}(\mathrm{cal})=6.53+1 \% \operatorname{Tg}(\mathrm{K}),(12)$. This proves the existence of $1 \%$ elongation limit in under $0^{\circ} \mathrm{C}$.

\subsection{The Total Numbers of Level (New Dimension) 18;Elementary Particles 17 and Molecules One}

Traditional thought of high dimension means to put a new axis to three axis in $3 \mathrm{D}, \mathrm{x}, \mathrm{y}$ and $\mathrm{z}$-axis. For example, the new axis in 4D may be time. At new thought, elongation of axis in 3D takes change of high dimension . Those method change numerical dimension to qualitative level so that ranking goes up from $3 \mathrm{D}$ as starting point, first level. Molecule groups above $0 \mathrm{~K}$ are formed $3 \mathrm{D}$, which separate 8 groups in one level., giving unit temperature $39 \mathrm{~K}$ from $273 \mathrm{~K}$ / 7 . High level starts from temperature under $0 \mathrm{~K}$, reaching up to $-653 \mathrm{~K}$.. Those consists of 16.74 levels obtained from $39 \mathrm{~K}$ per level which is equivalent group , 653K / 39K $\fallingdotseq .16 .74$.This is correspondent to numbers of elementary particles 17, including Higgs's particle. It shows that $\alpha$ refers to elementary particles and make a confirmation of this theory .The total number of level needs to add one of above $0 \mathrm{~K}$ to the number of under $0 \mathrm{~K}$. That shows 17.74 . The upper limit of $-653 \mathrm{~K}$ and the lower limit of $0^{\circ} \mathrm{C}$ give indefinite domain in level or group ,making a decimal fraction .

\subsubsection{Exceptional Limit Domain in Both End of Line}

Although the relation between $\alpha$ and temperature is a linear as shown (2), the both end of line give hyperbolic curve in limit domain. The latter, which $\alpha$ of nearly $0^{\circ} \mathrm{C}$ is extreme low ,shows about 1 of $\mathrm{L}$ unit ,because it is a normal side occupied by nearly $39 \mathrm{~K}$ in $39 \mathrm{~K}$ unit ,( nearly $39 \mathrm{~K})$ / $39 \mathrm{~K} \fallingdotseq 1$ The thinking of nearly $0^{\circ} \mathrm{C}$ can adapt similarly to $-653 \mathrm{~K}$. The former of the top ,upper limit ,obtained by $39 \mathrm{~K}$ is given as 0.74 not to reach full of 1 , which leave for maximum $\alpha$ of infinite value $\alpha$ of nearly $-653 \mathrm{~K}$,final temperature, is in inverse proportion to temperature by changing hyperbola from a linear relation of $1 \% \alpha$. The reason of lack causes changing temperature by hyperbola. If $\alpha$ becomes 10 times , $10 \% \alpha$, temperature decreases $1 / 10$ so that $1{ }^{\circ} \mathrm{C}$ is $0.1^{\circ} \mathrm{C}$. From the result, it would bring 0.74 of $\mathrm{L}$ unit to nearly 1 . Therefore, the total number of level is given as 18 , an integer.

\subsubsection{Relation between Level and $\alpha$}

Molecule groups above $0 \mathrm{~K}$ form $3 \mathrm{D}$ by separating 8 groups in one level. Here, $3 \mathrm{D}$ is $1 \mathrm{~L}$ and $4 \mathrm{D}$ means $2 \mathrm{~L}$. Where $\mathrm{L}$ stand for Level, used for different dimension. Each $\mathrm{L}$ is originated every $39 \mathrm{~K}(0.39 \mathrm{cal}) . \alpha$ is 2.73 at $0 \mathrm{~K}$ by (2). But this shows the value of $2 \mathrm{~L}$ not to belong $1 \mathrm{~L}$. There are two different viewpoint in place that Fig.4a shows a special case and Fig.4b shows usually value which moves from low $\mathrm{L}$ to high one .The equation is given as $2.73+(\mathrm{nL}-2) \times 0.39$ Where $\mathrm{n}$ is number of $\mathrm{L}$.For example, $3 \mathrm{~L}$ is 3.12 . Ups and

downs on borderline of each $\mathrm{L}$, is to have the same $\alpha$, for example ,upper end of $1 \mathrm{~L}$ and start of $2 \mathrm{~L}$ is 2.73 .But ,the value of lower ranking $\mathrm{L}$ side shows approaching it because of taking a hyperbolic curve. In case of this style ,1L shows as , $0 \sim$ under 2.73 and $2 \mathrm{~L}$ is , $2.73 \sim$ under 3.12 . see Fig.4b . Fig.4a shows the opposite movement to lower L, giving a single value which shows only the sort for the explanation,

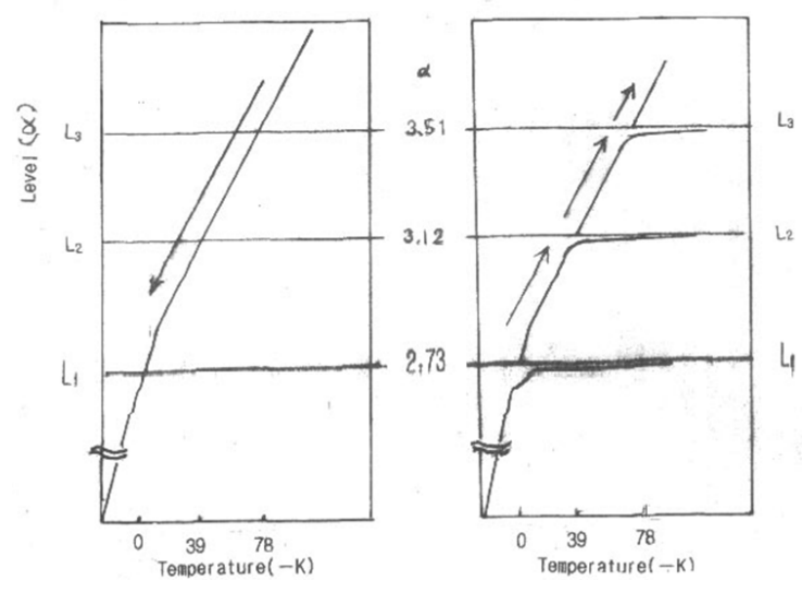

Fig. 4. Relation between level or $\alpha$ and temperature $(-K)$

Temperature of horizontal axis shows a point of every$39 \mathrm{~K}$ from $0 \mathrm{~K}$. Level and $\alpha$ of vertical axis shows the corresponding value to every $-39 \mathrm{~K}$, for example , L of $39 \mathrm{~K}$ is $\mathrm{L}_{2}$ and $\alpha$ is 3.12 . There is a difference between a transference to higher and lower level. (a) shows the mobile ability to lower level, which means to be able go freely .From 17 level of the upper limit, it could move up to $1 \mathrm{~L}$. (b) shows that a movement to higher level is impossible, only approaching them .

\subsection{Ranking and Characteristic of Level in Soul}

The borderline of $0 \mathrm{~K}$, between $1 \mathrm{~L}$ and $2 \mathrm{~L}$, separates a heterogeneous space. It may be divided that $2 \mathrm{~L}$ of elementary particles is the world of soul and $1 \mathrm{~L}$ of molecules is living one as mentioned above.$\alpha$ of $2 \mathrm{~L}$ and $1 \mathrm{~L}$ on the borderline, show similar the number ,2.73 and under 2.73 . But there are a great difference between them. In case of 1L, mutual binding work between atoms affects to lose a movement of atom . Target length of (9) becomes nearly zero. Time is given as ,target length / velocity and $\alpha$ also can put to velocity from(11). The result brings that $3 \mathrm{D}$ of this world has only a fixed time and space. $2 \mathrm{~L}$ can move freely without any constraint. .The target length becomes large and time is given a wide range . Soul could take any time and size of space an instant and travel in the past and future, though it is impossible in 1L. Soul of higher level is able to have more long time than lower one. Although from lower level can't move up the upper rank, the opposite is possible because high level has all $\alpha$ of lower level. Final level of $18 \mathrm{~L}$, the highest spirit, can transfer to all $\mathrm{L}$, taking any time and space freely. All souls encounter with 1L 


\section{New Thought of Gravitation}

Acceleration of gravitation is given as $9.81 \mathrm{~m} / \mathrm{sec}$. but mass is functionless. The reason of mechanism is not clear for a attractive force needs mass. The phenomenon related with velocity and acceleration can handle as the flow, formed by elementary particles. Fig .5 shows the flow of elementary particles, generating a gravitation. No .1 is the flow of elementary particles circulating between zero-level and ground of earth. No, 2 is a falling material by gravitation to flow down riding on No 1 .

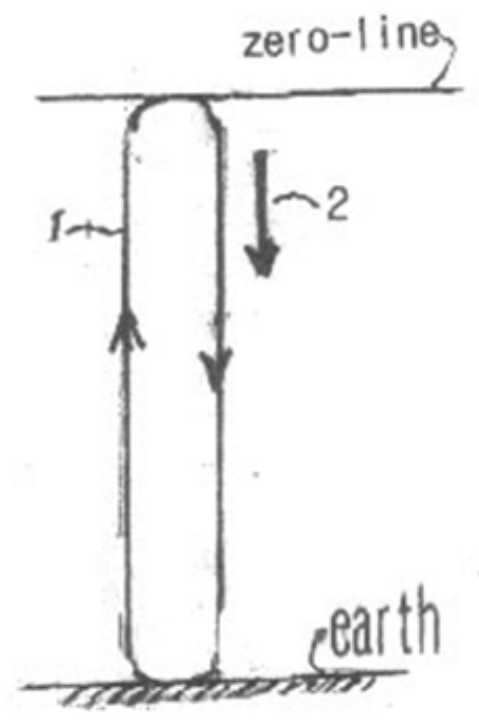

Fig. 5. The flow of elementary particles

No .1 is the flow of elementary particles circulating between zero-level and ground of earth. No, 2 is a falling material by gravitation to flow riding on No 1 .

\subsection{The Cosmos and Elementary Particles}

The cosmos was created to expand extraordinarily high heat by the big bang. Because a acceptor of .spreading heat existed, space and temperature .happened. If it were nothing, heat would pass without dropping in there To be precise, elementary particles with heat mean to spread. Molecules and elementary particles mean to form space and temperature .Ultimately, elementary particles making molecules ,form the cosmos .It is no space ,packed close in everywhere of cosmos, without them. It can understands easily to assume a existence of elementary particles for dark matter . The question is why the dark is .

\subsection{The Reason of Darkness in the Dark Matter}

Elementary particles seem to give a stationary state because of a composition restricted in molecule, even if it have over the velocity of light.A phenomena of molecule can be applied to elementary particles . Figure shows a relation between temperature and movement of gas molecule, taking a circular movement. Those don't flow out, which gives the reason of the dark. Explosion of a nova make an exception in a outside cause.

\section{New Thought Based Elementary Particles}

\subsection{Over the Velocity of Light in the Light}

The light is made from a composite rays. If all rays in them were the same position, colors could not happen, because their wavelength overlap perfect. A close difference between them brings the result .It can explain through Figure. When the rays in light, in spite of different velocity, reach the same radius showed as Fig. 6 .causing to make the order in a close time .This fact brings some important examples. One is given a possibility a existence of over the velocity of light in the light.

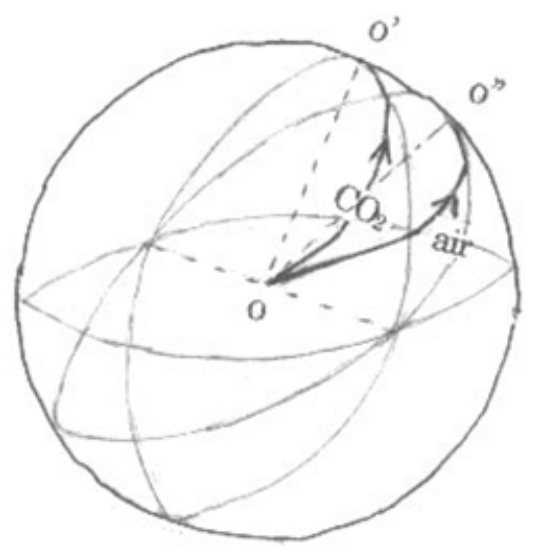

Fig 6. Flight of gas molecule

$\mathrm{O}$ is starting point of molecule .o' is end point of $\mathrm{CO}_{2}$ flight and o" is one of air . $\mathrm{o}^{-} \mathrm{o}$ ' and $\mathrm{o}^{-} \mathrm{o}$ " is radius of a sphere . Flight course of each molecule gives the great-circle in a cross section

\subsection{The Heisenberg's Principle and Over the Velocity of Light and Time}

Relation between position and velocity in the quantum mechanics is uncertainly, which no one can fix two at a time ,by Heisenberg's principle .[5] At elementary particles ,the position which a changing temperature causes to happen a momentum of gas molecule, is given as the locus of circumference .It is not able to fix a anywhere because of circumference. The velocity in momentum is related to time through the distance .It is clearly that the position and time of elementary particles can't fix at a time by new understanding of Heisenberg's principle .The traditional principle is abstract content but new one shows a concrete movement. Searching for over the velocity of light is trying often today, when an experiment is down by a huge accelerating machine .But the result can't get because relation the starting point and time is uncertainly by new understanding of Heisenberg's principle .Over the velocity of light belongs a theoretical field .. 


\section{Conclusion}

The existence of elementary particles make to clarify some physical phenomena after Einstein's theory .Those are the essence of the big bang ,causing space and temperature as a acceptor of heat and give $-653 \mathrm{~K}$. .Forming and demolition of molecules by them show life and death, giving the essence of life called soul too . Einstein's equation on Brownian movement shows a movement of water molecule . New viewpoint changes that cause those thermal expansion or shrinkage. A little different temperature at local places of water happen Brownian movement $\alpha$ of thermal expansion has the best factor for new dimension showed the structure of the cosmos ,giving entropy ,time, temperature ,space and additional properties of element. Molecule groups above $0 \mathrm{~K}$ are formed 3D, which separate 8 groups in one level., giving unit temperature $39 \mathrm{~K}$. Up to $-653 \mathrm{~K}$. from $0 \mathrm{~K}$, modified value consists of 17 levels . This is correspondent to numbers of elementary particles 17 . This would be to make a confirmation of the theory. $1 \mathrm{~L}$ of molecules is this world and over $2 \mathrm{~L}$ is separated soul world. Soul could take any time and size of space an instant and travel in the past and future .Soul of higher level is able to have more long time than lower one. Although from lower level can't move up the upper rank, the opposite is possible because high level has all $\alpha$ of lower level. Final level of 18L, the highest spirit, can transfer to all level. , All souls encounter with 1L .Elementary particles in everywhere prove dark matter. A circular movement of gas molecule gives the reason of the dark without flowing away as light. . The flow of elementary particles which circulates through the surface of earth generates the gravitation. A material falls to flow down riding on them. A light of composite rays, with each different velocity, cause to make the order in a close time by a circular course .This understanding gives a possibility a existence of over the velocity of light in the light. Relation the starting point and time is uncertainly by new understanding of Heisenberg's principle .Over the velocity of light belongs a theoretical field.

\section{References}

[1] Y. Matsushita, "New theory on physical property of polymer, From cured resin to linear polymer, Tm and $\mathrm{Tg}$ and Strength”J. Appl. Polym. Sci.vol. 97 2005.,pp..1467 1475.

[2] Y. Matsushita, "Study on the new segment in new theory of polymer", J. Appl. Polym. Sci. vol.106. 2859, 2007,pp $2859-2862$.

[3] Y. Matsushita, Science (Report). under submission

[4] S.Ono,Butsuri Kagak I (physical chemistry ) , Kyoritsu Shupan ,Tokyo ,1972,pp.118..

[5] H.Ooguri .Juryoku towa nanika ( What is gravity ), Gen To Sha ,Tokyo ,2012,pp.180 